\title{
On the Strategy of Shaping Rural Human Settlement Environment in Jiangsu Province from the Perspective of Beautiful Pastoral Country
}

\author{
Yuan Xinguo ${ }^{1,2, *}$, Wang Xingping ${ }^{1}$ \\ ${ }^{1}$ School of Architecture, Southeast University, Nanjing210096, Jiangsu, China \\ ${ }^{2}$ Jiangsu Provincial Urban Planning and Design Group Co., Ltd., Nanjing 210036, Jiangsu, China
}

\begin{abstract}
Beautiful pastoral country construction is an important step for Jiangsu Province to fulfil the mission of "being a leader, a model and a front-runner" in rural revitalization, and it has become an important part of realizing the beautiful province of Jiangsu. By means of data comparison, literature analysis and logical analysis, it is possible to outline the current characteristics of unbalanced regional development, uneven distribution of characteristic resources and mismatch of the "agriculture, rural areas and farmers" policies with the new development requirements in the province, and by referring to the model of rural revitalization in the "six along" areas, systematic thinking and planning of "agriculture, rural areas and farmers" policies and other strategies, with focus on the systematic construction of agriculture, rural areas and farmers, is helpful to improve the habitat environment in Jiangsu in all respects. The results show that the strategy of building beautiful pastoral country in northern, central and southern Jiangsu should be adapted to local conditions; Jiangsu should take the lead in the construction of beautiful pastoral country in the "six along" areas; the key to the construction of beautiful pastoral country lies in the industrial development in rural areas. The two should be closely coordinated and driven by each other to jointly achieve the modernization of agriculture and rural areas.
\end{abstract}

\section{Introduction}

The Eighth Plenary Session of the 13th CPC Jiangsu Provincial Committee proposed the theme of building "Beautiful Jiangsu" from a high starting point. The construction of beautiful pastoral country is an important action for the grand blueprint of Jiangsu province with "strong economy, rich people, beautiful environment and high degree of social civilization", to highlight the beauty and richness of villages in Jiangsu as "waterland of fish and rice". Jiangsu promotes the construction of beautiful pastoral country across the province as an important starting point to promote the overall improvement of rural habitat environment. As the province has since 2011 been carrying out village environment improvement, the construction of characteristic rural villages and other campaigns ${ }^{[1]}$, a better overall foundation for the construction of beautiful pastoral country has been established, but it is urgent to plan in advance and make precise breakthroughs in regional development path, key promotion space, "agriculture, rural areas and farmers" policy reform and other areas.

\section{Necessity of the construction of beautiful pastoral country in Jiangsu}

\subsection{An important part of building beautiful Jiangsu}

The construction of high-quality and beautiful Jiangsu is indispensable for Jiangsu to take the lead in the construction of beautiful China. Beautiful Jiangsu should not only have the beauty of livable cities, but also the beauty of urban characteristics, and more importantly, and the beauty of pastoral country. Rural areas are the integration of human residential space and natural space and beautiful pastoral country reflects the harmonious coexistence of human and nature. The spatial layout, development path and motivational mechanism of the beautiful pastoral country should be explored as soon as possible to continuously improve the quality of rural habitat.

\subsection{Practice of rural revitalization strategy in Jiangsu}

The comprehensive promotion of the construction of beautiful pastoral country in Jiangsu, showing the vision

\footnotetext{
* Corresponding author: 282293994@qq.com
} 
of a beautiful pastoral country with "excellent ecology, beautiful village, special industry, rich farmers, strong collective and good rural customs", is the concrete practice of the general requirement of the rural revitalization strategy for "prosperous industry, ecological livability, livable ecology, civilized rural customs, effective governance, and rich life" in Jiangsu.

\subsection{Undertaking the "critical task" of Jiangsu's rural revitalization leading the country}

The national rural revitalization strategy proposes phased goals of the "three steps forward" to achieve all-round rural revitalization by 2050 . The rural areas in the eastern, central and western regions of China are at different stages with different drivers for growth, leading to differences in the strategies and paths taken to achieve the goals of rural revitalization. Since the beginning of the reform and opening up policy, Jiangsu has been a "pioneer region" for rural reform exploration. According to the data released by the National Bureau of Statistics, Jiangsu was the only provincial administrative unit (province, autonomous region and municipality directly under the Central Government) in China (excluding Hong Kong, Macao and Taiwan) with the added value of the primary industry per unit area exceeding 40 billion yuan / 10,000 square kilometers in 2019(Fig.1 $)^{[2]}$. Under the new situation, Jiangsu, as a model province for the construction of beautiful China, should take up the "crucial task" of exploring and demonstrating all-round revitalization of the countryside in different regions across the country with the experience in building beautiful pastoral country in different regions of the province.

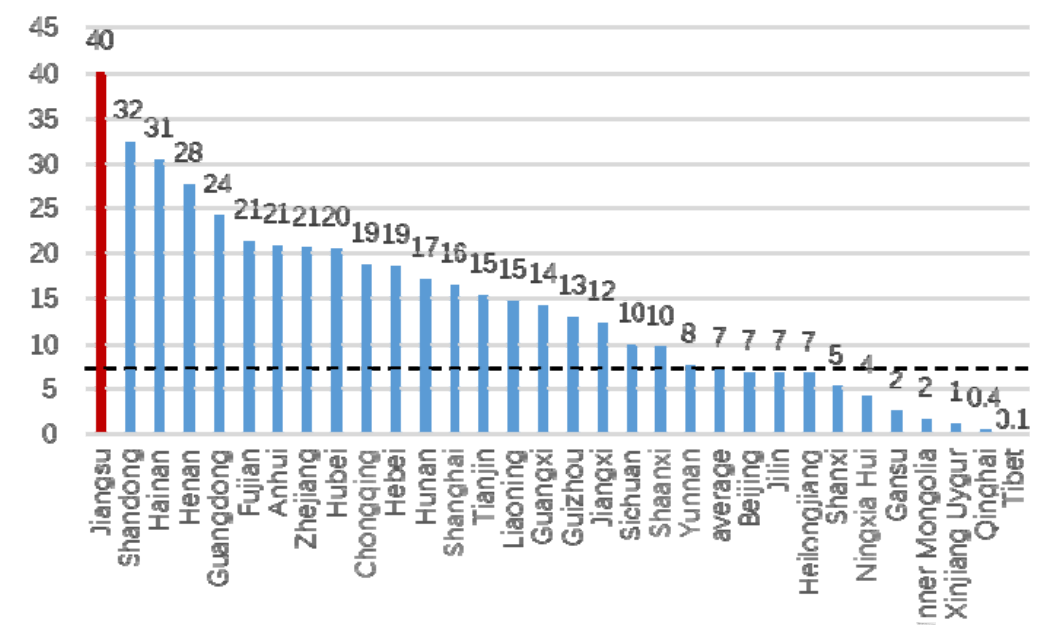

Fig. 1. Added value of primary industry per unit area of provincial administrative units in mainland China (unit: billion yuan/10,000 square kilometers)

\section{Main features of the construction of beautiful pastoral country in Jiangsu}

\subsection{Imbalanced regional development}

Jiangsu has an imbalanced and insufficient development in the southern, central and northern regions. According to GDP and population released by the National Bureau of Statistics, in 2018, southern Jiangsu, with a per capita GDP of more than 160,000 yuan, was one of the highest regions in China; the GDP per capita in central Jiangsu was 115,000 yuan, comparable to the provincial average; while about 70,000 yuan in northern Jiangsu, slightly higher than the national average but only $44 \%$ of that in southern Jiangsu[1]. The quality of farm houses and the appearance of villages in different regions of Jiangsu, similar to the level of economic development, also showed a significant difference. And such difference was also found in the movement of rural population, specifically, the net inflow of rural population in southern Jiangsu reached 23.5\% (Table 1), while the net outflow in central and northern regions of Jiangsu was $4.5 \%$ and $7.0 \%$, respectively ${ }^{[3]}$.

Table 1. Rural population inflow and outflow by region in Jiangsu

\begin{tabular}{|c|c|c|c|c|}
\hline Name of region & $\begin{array}{c}\text { Registered } \\
\text { village } \\
\text { population } \\
\mathbf{( 1 0 , 0 0 0 )}\end{array}$ & $\begin{array}{c}\text { Resident village } \\
\text { population } \\
\mathbf{( 1 0 , 0 0 0 )}\end{array}$ & $\begin{array}{c}\text { Immigrant } \\
\text { village } \\
\text { population } \\
(\mathbf{1 0 , 0 0 0 )}\end{array}$ & $\begin{array}{c}\text { Ratio of immigrant } \\
\text { population to } \\
\text { registered } \\
\text { population (\%) }\end{array}$ \\
\hline Southern Jiangsu & 659 & 814 & 155 & 123,5 \\
\hline Central Jiangsu & 937 & 895 & -42 & 95,5 \\
\hline Northern Jiangsu & 1875 & 1743 & -131 & 93,0 \\
\hline Jiangsu Province & 3471 & 3453 & -18 & 99,5 \\
\hline
\end{tabular}

\subsection{Uneven distribution of featured resources}

Jiangsu is the convergence of rivers, lakes and seas, rich in cultural resources. Its featured resources, distributed in a pattern of more in the south and less in the north, more in the west and less in the east, constitute a vital substrate for the beautiful pastoral country construction (Fig.2). The construction of beautiful pastoral country 
should not only strengthen the role of Jiangsu countryside as an important guarantee for national food security, but also highlight the demonstration effect of exploring the integration of multiple functions such as production, living, ecology and leisure in the countryside of the pioneer regions. Natural landscape and cultural

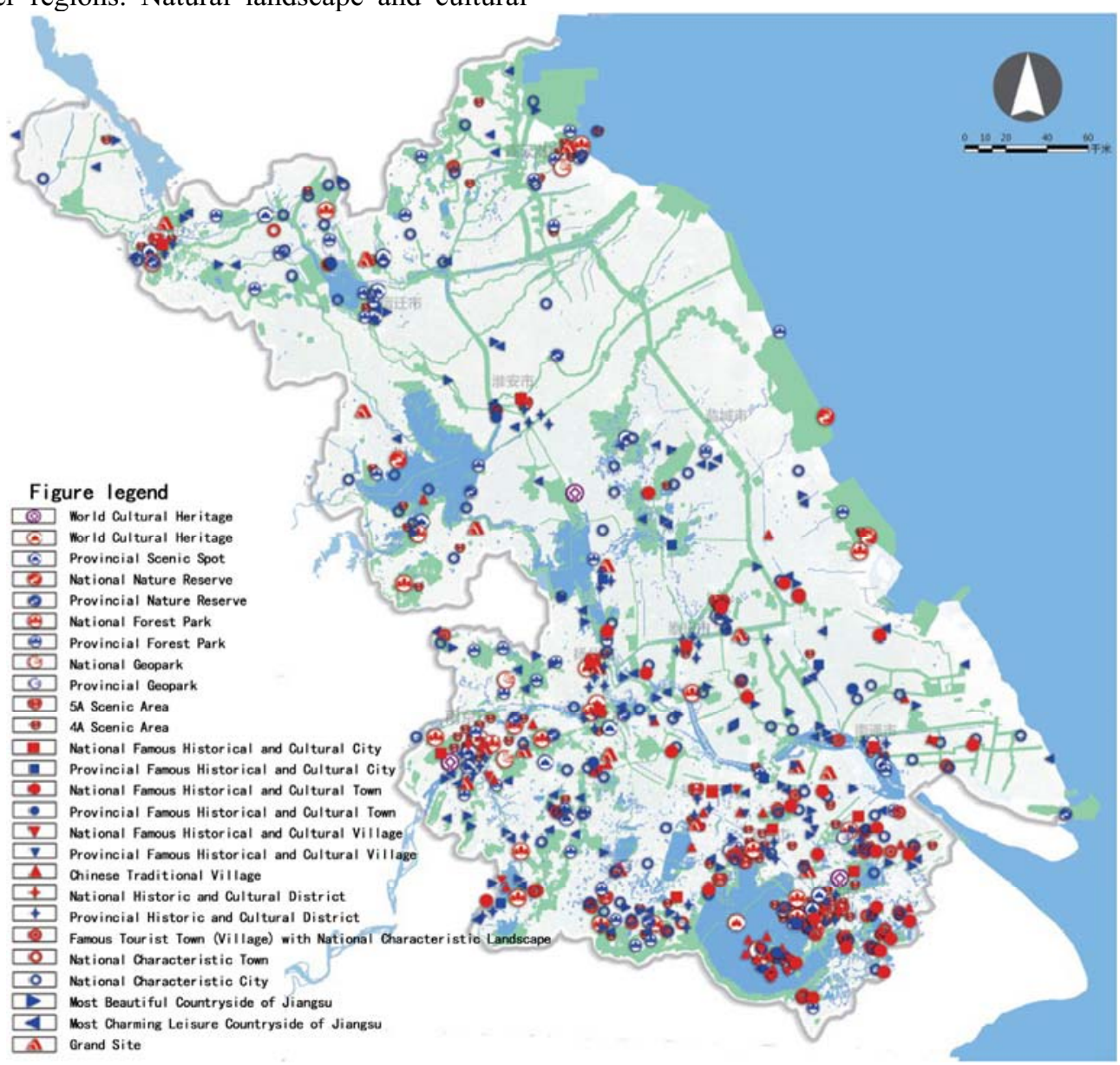

Fig. 2. Summary map of featured resources in Jiangsu ${ }^{[4]}$

\subsection{Mismatch between "agriculture, rural areas and farmers" policies and new requirements}

Jiangsu has made remarkable achievements in recent years in solving the issues relating to "agriculture, rural areas and farmers", with the initial realization of largescale agriculture and increasing mechanization; the reform of "construction land in rural town planning areas, rural farmland and rural construction land" has been launched on a pilot basis, with continuous improvement of the living environment and public service facilities; the farmers' income has been increasing with the widening of employment path. However, Jiangsu is facing new problems and challenges in the issue of "agriculture, rural areas and farmers" and needs further breakthrough and refinement of policies, mainly in the following areas: agricultural modernization needs to be further improved, especially the "bottleneck" in the level of agricultural research should be broken through; market participation in rural construction should be further increased, as the lack of implementation rules for the promotion of rural land reform policy, the difficulty resources should be fully utilized to provide Jiangsu with quality and soulful high-level beautiful pastoral country with considerable "outer beauty" and perceptible "inner beauty".

in popularizing the policies on withdrawal of homestead and marketing of collective commercial land, and the fact that the mechanism of input and benefit from all parties has not yet been fully established have led to the failure to achieve the expected effect of encouraging the introduction of social capital in rural construction; specialization of farmers needs to be further improved, as with the development of modern agriculture in the direction of science and technology, high efficiency and horticulture, there are higher requirements for farmers' professional quality and skills. 


\section{Suggestions for the construction of beautiful pastoral country in Jiangsu}

\subsection{The improvement of rural housing is a project for the benefit of the people in line with the actual conditions of Jiangsu, and it should be promoted across the province according to the regional differences}

The high promotion level of the rural housing improvement currently being carried out in northern Jiangsu has greatly improved the rural living environment and the intensive use of land, leading to the high satisfaction of farmers. As a good policy for the benefit of the nation and the people, it has been well received. However, due to years of restrictions on rural housing renovation and rapid urbanization in Jiangsu, the aging and vacancy problems of rural housing in the central and northern regions of Jiangsu have emerged, and the time has come for all-round improvement of farmers' housing conditions in the province. For the problem of imbalanced regional development in the province, it should be tailored to local conditions and differential policies.

Northern Jiangsu should promote rural housing improvement and modern agriculture linkage development, continue to renovate and build a number of new rural settlements, and change the spatial pattern of the countryside in the era of traditional farming civilization, to form a spatial pattern suitable for the modern agricultural production mode; coordinate the planning and layout of rural settlements and modern agricultural parks to promote the linkage of production and village; guide agriculture to the path of the linkage of "farmland standardization + mechanization in methods + idea scientificalization" from large-scale agriculture to modern agriculture, to improve agricultural production efficiency and technology, and attract scientific researchers and professional farmers to engage in rural revitalization.

Central Jiangsu should promote the linkage development of rural housing improvement and agricultural manufacturing; encourage the appropriate gathering of settlements and encourage the interaction between village layout and modern agricultural spatial pattern; make overall planning and coordination for the linkage between rural settlements and parks such as agricultural parks, industrial parks and tourism parks; guide the linkage of "large-scale agriculture + agricultural processing + circulation and consumption" from agricultural produce to agricultural products in the primary, secondary and tertiary industries, to increase the added value of agricultural produce and attract migrant workers to be employed in their hometowns.
Southern Jiangsu should promote the linkage development of rural housing improvement and rural tourism; guide the local and nearby establishment of rural settlements, optimize the natural pattern of village space, agricultural space and ecological space with mutual penetration; encourage the linkage development of natural endowment and beautiful pastoral country with superior cultural heritage, solve the contradiction between small and dense villages and diversified functional demands, integrate the village, agricultural and ecological spaces of rural clusters, jointly undertake such composite rural tourism functions as natural science popularization, landscape touring, leisure and vacation, cultural experience, health care and mind nourishing, to explore version 1.0 of rural revitalization across the board based on the concept of linkage development; guide the linkage mode of "leisure agriculture + making by hand + rural tourism" from beautiful ecology to beautiful economy in the primary secondary and tertiary industries, to increase the added value of the industry and attract urban talents to start businesses in the countryside.

\subsection{Construction of beautiful pastoral country is a long-term project, and the "six along" areas should be built into a model of rural revitalization}

There will be 1,000 characteristic pastoral villages and 10,000 beautiful and livable villages established throughout the province by 2025 , accounting for less than $10 \%$ of the current number of natural villages. The construction of beautiful countryside in Jiangsu, while emphasizing the balanced development of the whole area, should closely follow the idea of linking "four along" areas, that is, areas along the Yangtze River, areas along rivers, areas along lakes and areas along the coast in the construction of beautiful Jiangsu, and further expand to areas along mountains and areas along the important traffic corridors, and push forward the development selectively in stages to build the "six along" areas into a rural revitalization model that is more attractive than cities with picturesque scenery and harmonious relationship between people by 2035 .

The construction of beautiful pastoral country should stick closely to the province's characteristic spatial system. To implement the Strategic Planning for Urban and Rural Spatial Characteristics of Jiangsu, the construction of pastoral country should closely stick to the key characteristic spatial system framework of "eight corridors and twelve areas" in the province (Fig.3), and establish a regional spatial pattern with their own characteristics, strengths and beauty relying on the important characteristic landscape corridors and characteristic landscape areas. 


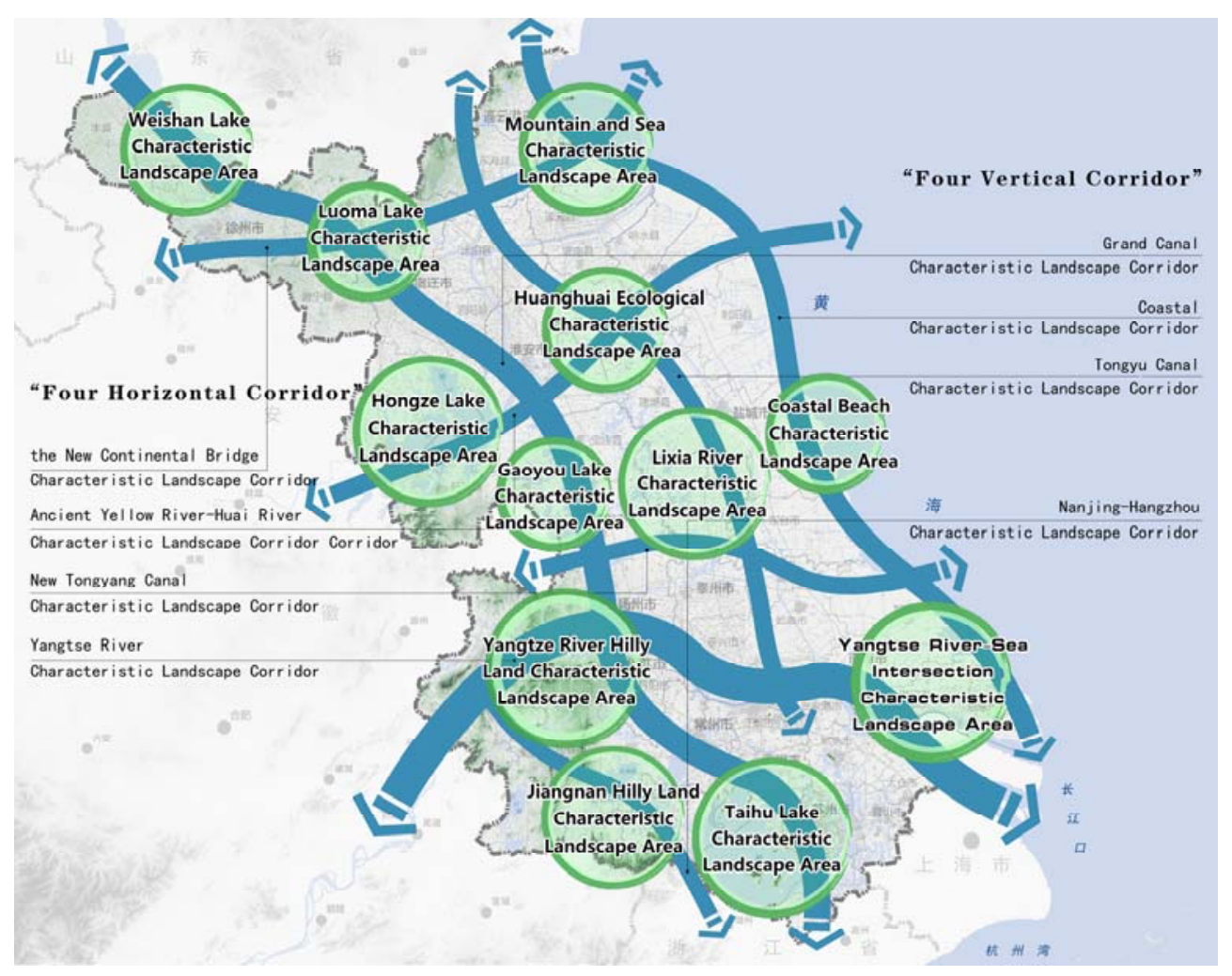

Fig. 3. Planning diagram of key characteristic spatial system in Jiangsu ${ }^{[4]}$

A beautiful pastoral country belt should be created along the characteristic landscape corridor. Relying on the featured resources along the characteristic landscape corridor, efforts should be made to facilitate the construction of beautiful pastoral country belts in sections and layers, build regional scenic roads, form regional and thematic beautiful pastoral country tourism lines, and weave a net in the whole province.

Beautiful pastoral country groups should be built in the characteristic landscape area. Relying on the featured resources in the characteristic landscape area, beautiful pastoral country groups should be built by classification and a cross-administrative coordination mechanism should be established to seek common ground and stagger development in function, synergize and achieve linkage development in industry, implement systematic connection and integrate development in space, protect and nurture quality development in ecology, provide differential rationing and share development in services, and identify values and explore co-rule development in governance.

\subsection{As the construction of beautiful pastoral country is a complex project, an advance area should be planned for "agriculture, rural areas and farmers" policies with systematic thinking}

The rural reform with the issue of "agriculture, rural areas and farmers" as the core runs through the entire course of reform. The issue of "agriculture, rural areas and farmers" is global, important and fundamental in nature, and it is urgent to explore the "agriculture, rural areas and farmers" policies with systematic thinking, to stimulate the vitality of all entities, factors and markets, and to promote the high-quality development of beautiful pastoral country in Jiangsu.

Breakthroughs in modern agriculture paths should be actively explored. High-standard farmland should be built on a large scale to explore the path of mechanization of agriculture in Jiangsu in different farming conditions and in different processes for different crops. It should pilot the construction of provincial agricultural high-tech industry demonstration zones (hereinafter referred to as "agricultural high-tech zones") across the board in towns with good agricultural infrastructure conditions, to promote the alliance between the agricultural high-tech zone and scientific research institutions, establish an innovation process chain of "scientific research - transformation promotion", explore the agricultural technology innovation adapted to the climate, soil and hydrological conditions in Jiangsu, conduct pilot test and incubation in situ, and actively spread it to the rest regions in the province or even other provinces when achieving a successful result.

Rural land reform policies should be actively explored. The reform of "construction land in rural town planning areas, rural farmland and rural construction land" should be closely followed to push collectives and farmers to release their idle and idle resources with substantial and sustainable returns, to raise the efficiency of production and operation. Rural land should be encouraged to operate in a large-scale form to develop modern agriculture. Families who settle in cities and towns should be encouraged to withdraw from their homestead, and a diversified compensation mechanism for the withdrawal should be explored. It should define the collective construction land market rules for 
commercial purposes, guide the priority use of revitalized rural construction land index for improving rural infrastructure, public welfare and cultural tourism facilities, attract social capital to the construction of beautiful pastoral country, promote sustainable valueadded and long-term returns on investment, and explore input and benefit mechanisms for collectives, social capital, and land expropriated farmers.

The cultivation mode of professional farmers should be actively explored. Talents are the key to rural revitalization, as "people" is the best factor to drive the close linkage and deep integration between urban and rural areas in terms of market, capital, information, technology, management and philosophy ${ }^{[5]}$. Scientific researchers should be encouraged to go to the countryside and focus on breakthroughs in agricultural technology innovation, especially in breeding, intelligent agriculture and intelligent agricultural equipment and other "bottlenecks" in the field of agriculture in China, to achieve innovation with breakthrough from " 0 to 1 " and transformation from "1 to 10". Professional and technical farmers should be trained to ensure the largescale production based on agricultural science and technology and to realize the promotion of innovation from "10 to N". Efforts should be made to attract service creators to the countryside to start businesses and promote continuous innovation in food, housing, transportation, entertainment, shopping and tourism in rural tourism. Rural volunteer teams or members should be dispatched to serve in rural policy research and project implementation $^{[6]}$. The identification system for rural researchers, professional farmers, service creators, rural craftsmen and volunteers should be promoted on a pilot basis, and policy preferences should be given to promotion of professional titles and application of projects.

\section{Conclusion}

The focus of the beautiful pastoral country construction is on the multiple compound industries, which depend on the characteristic resources for development. There is a spatial coupling between the construction of beautiful pastoral country and the characteristic resources, so the construction of beautiful pastoral country in Jiangsu should be carried out first in the "six along" areas. Due to the differences in development, the construction of beautiful pastoral country in northern, central and southern Jiangsu also differs. Beautiful pastoral country should be integrated with the planning and layout of modern agricultural parks, especially in terms of industrial development, to promote the linkage between industry and villages. In order to guide the upgrade from large-scale agriculture to modern agriculture featuring "farmland standardization + mechanization in methods + idea scientificalization" and to improve agricultural production efficiency and technology, the central Jiangsu should make overall planning and coordination for the linkage between rural settlements and parks such as agricultural parks, industrial parks and tourism parks, and guide the linkage of "large-scale agriculture + agricultural processing + circulation and consumption" from agricultural produce to agricultural products in the primary, secondary and tertiary industries, to increase the added value of agricultural produce. The southern Jiangsu should encourage the development of rural tourism, undertake such composite rural tourism functions as natural science popularization, landscape touring, leisure and vacation, cultural experience, health care and mind nourishing.

\section{References}

1. Zhou Lan, Zhao Qinghong, et al. Pastoral Country: Jiangsu's Exploration of Rural Revitalization through the Construction of Characteristic Pastoral Country[M]. Beijing: China Construction Industry Press, 2020, 7.

2. National Bureau of Statistics (NBS). http://www.stats.gov.cn/tjsj/

3. Jiangsu Province 2018 Village and Town Construction Annual Report[R]. Nanjing: Department of Housing and Urban-Rural Development of Jiangsu Province, 2019.

4. Zhou Lan, Zhang Jian. Exploration on the Method of Building Urban and Rural Spatial Characteristics from the Perspective of Provincial Level: A Case Study on "Strategic Planning for Urban and Rural Spatial Characteristics of Jiangsu" [J]. Urban and Rural Planning, 2019(02): 49-58.

5. Zhang Jing. "Industrial village chief" opens up a road to revitalize rural talents[N]. China Urban and Rural Financial News, 2020-07-29 (B03).

6. Liu Yungang, Chen Lin, Song Hongyang. Human Support Towards Rural Regeneration in Japan and Its Implications for Rural Revitalization of China[J]. Urban Planning International, 2020, 35(03): 94-102. 